\title{
Increase liquid oil production by huff-n-puff of produced gas in shale gas condensate reservoirs
}

\author{
James J. Sheng \\ Bob L. Herd Department of Petroleum Engineering \\ Texas Tech University \\ P.O. Box 43111, Lubbock, TX 79409 \\ United States of America
}

\begin{abstract}
Hugh shale resources available and low gas price turn the oil operators' activities to producing more liquid oil. The earlier studies from our research group and others show that huff-n-puff has the highest potential to improve oil recovery (IOR) in shale oil reservoirs, compared with common IOR methods of gas flooding and waterflooding. This paper is to extend the research to shale gas condensate reservoirs to evaluate the IOR potential. The simulation analysis approach is used.

The simulation results and discussions in this paper show that huff-n-puff injection of produced gases can produce more liquid oil in gas condensate reservoirs than gas flooding or primary depletion. This result is verified by all the simulated cases with different reservoir and fluid properties and operation conditions. The advantages of huff-n-puff over gas flooding are the early response to gas injection, high drawdown pressure, oil saturation decrease near the wellbore by evaporation, and overcoming the pressure transport problem owing to ultra-low permeability. The advantages become more important when the initial reservoir pressure is close to the dew point pressure, or the bottom-hole flowing pressure is low. The effects of injected gas composition, cycle time and soak time during the huff-n-puff process are investigated. A simple economic analysis is also conducted.
\end{abstract}

\section{[1]Introduction}

Generally, when the pressure is reduced, a liquid will vaporize to become a gas. However, in some special situation, when the pressure is reduced below a dew point pressure, a liquid forms from an initial gas phase, as shown in Fig. 1 from Point A to Point B. This phenomenon is called retrograde condensate. Such reservoir is called gas condensate reservoir where initially the fluid is in gas state in reservoir. To produce the gas condensate, the conventional practice is to maintain the reservoir pressure or even the bottom-hole well pressure of the production well above the dew point pressure by gas and/or water flooding (Hernandez et al., 1999). The reason is that, if the reservoir pressure is allowed to decline below the dew point, a considerable volume of valuable condensate may be lost in the reservoir because oil saturation is formed and it is more difficult for the liquid to flow to the surface compared with gas. When oil saturation is below a residual oil saturation, oil cannot be produced using a conventional producing method. In addition, gas productivity declines rapidly once the liquid is formed near the wellbore, because the liquid will block gas flow (Thomas et al., 1995). 


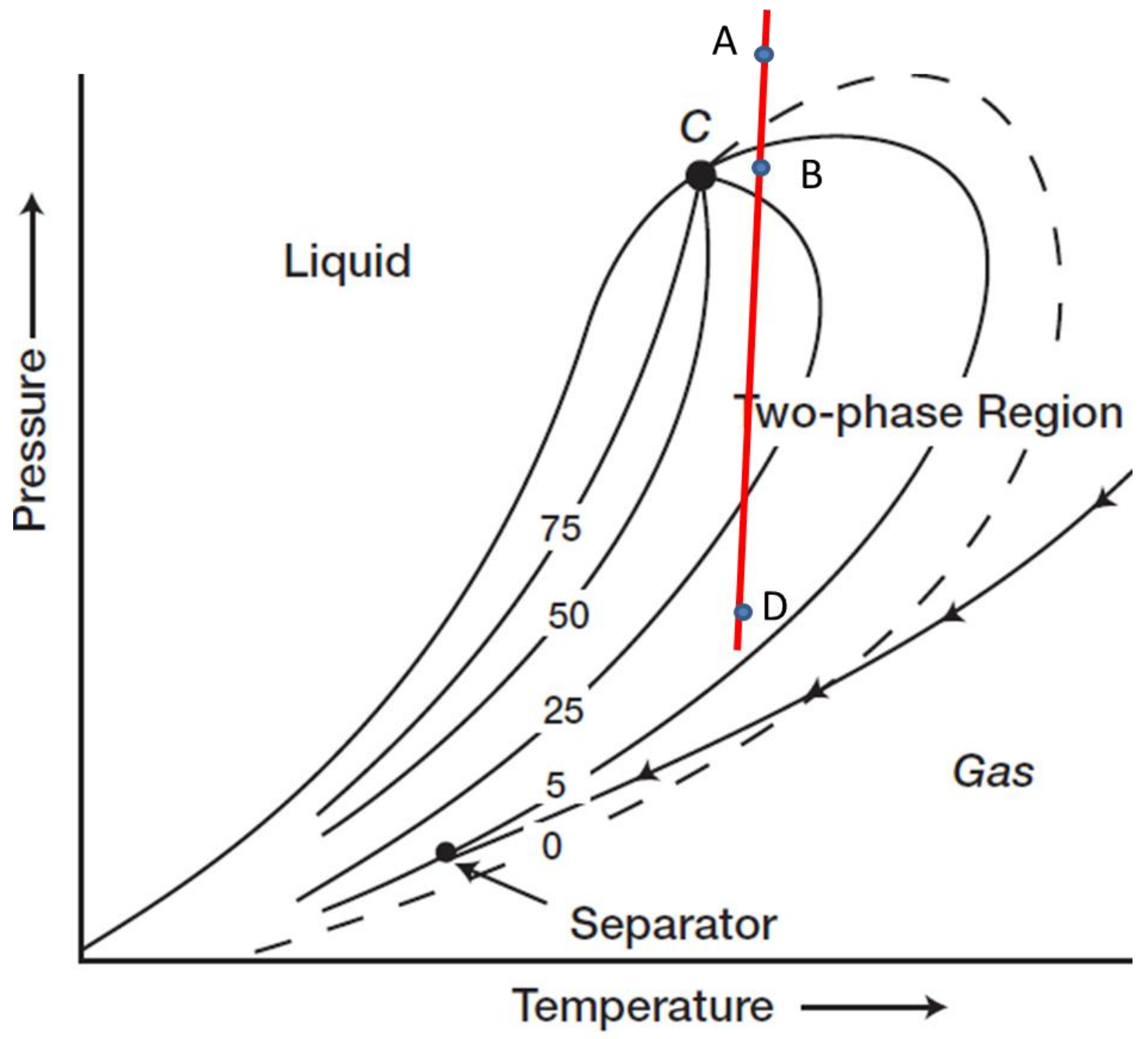

Fig. 1 - An example of $p-T$ diagram of a retrograde condensate

In a shale or tight gas condensate reservoir where the formation permeability is very low (nanoDarcy or micro-Darcy), if the well flowing pressure and/or the reservoir pressure is above the dew point pressure, the pressure difference between the reservoir pressure and well flowing pressure which is the drive force to produce gas condensate will be small, especially when the initial reservoir pressure is near the dew point pressure. Then the production rate will be low and the resulting total hydrocarbon recovery will be low as well.

To increase reservoir pressure, there are two methods: gas flooding and huff-n-puff. In the gas flooding, gas is injected through an injector, and fluids are produced from another producer. In the huff and puff gas injection, gas is injected to the reservoir through a well during the huff period, and fluids are produced from the same well during the puff period.

In our earlier work of huff-n-puff gas injection in shale oil reservoirs, we studied the pressure effect on oil recovery (Wan et al., 2013a, 2013b; Gamadi et al., 2013; Wan et al., 2014; Gamadi et al., 2014). By intuition, if the flowing pressure is above the minimum miscibility pressure (MMP), the injected gas will be fully miscible with the in-situ oil, then the oil viscosity will be 
decreased to the minimum and the oil will swell to the maximum. The oil recovery will be high. However, the simulation results in Fig. 2 show that higher oil recovery is obtained if a lower bottom-hole flowing pressure (BHFP) is used, even though the flowing pressure is lower than the MMP. The main reason is that as the flowing pressure is lower, the pressure difference between the reservoir and this flowing pressure (drive force) will be higher, so that flow rate will be higher according to Darcy's law. Apparently, one of the dominant mechanisms is pressure maintenance. According to the discussions and definitions in Sheng (2011), if the dominant mechanism is pressure maintenance, the gas injection process belongs to improved oil recovery (IOR). If the dominant mechanism is related to miscible flooding, the gas injection process belongs to enhanced oil recovery.

Similarly, in gas condensate reservoirs, to increase gas and oil production, the pressure drop should be high. The wellbore flowing pressure will be lower than the dew point pressure. When that occurs, the liquid oil will be accumulated at the wellbore, and the resulting gas saturation will be low. Then gas condensate rate will be lower, the corresponding liquid oil rate will be low as well.

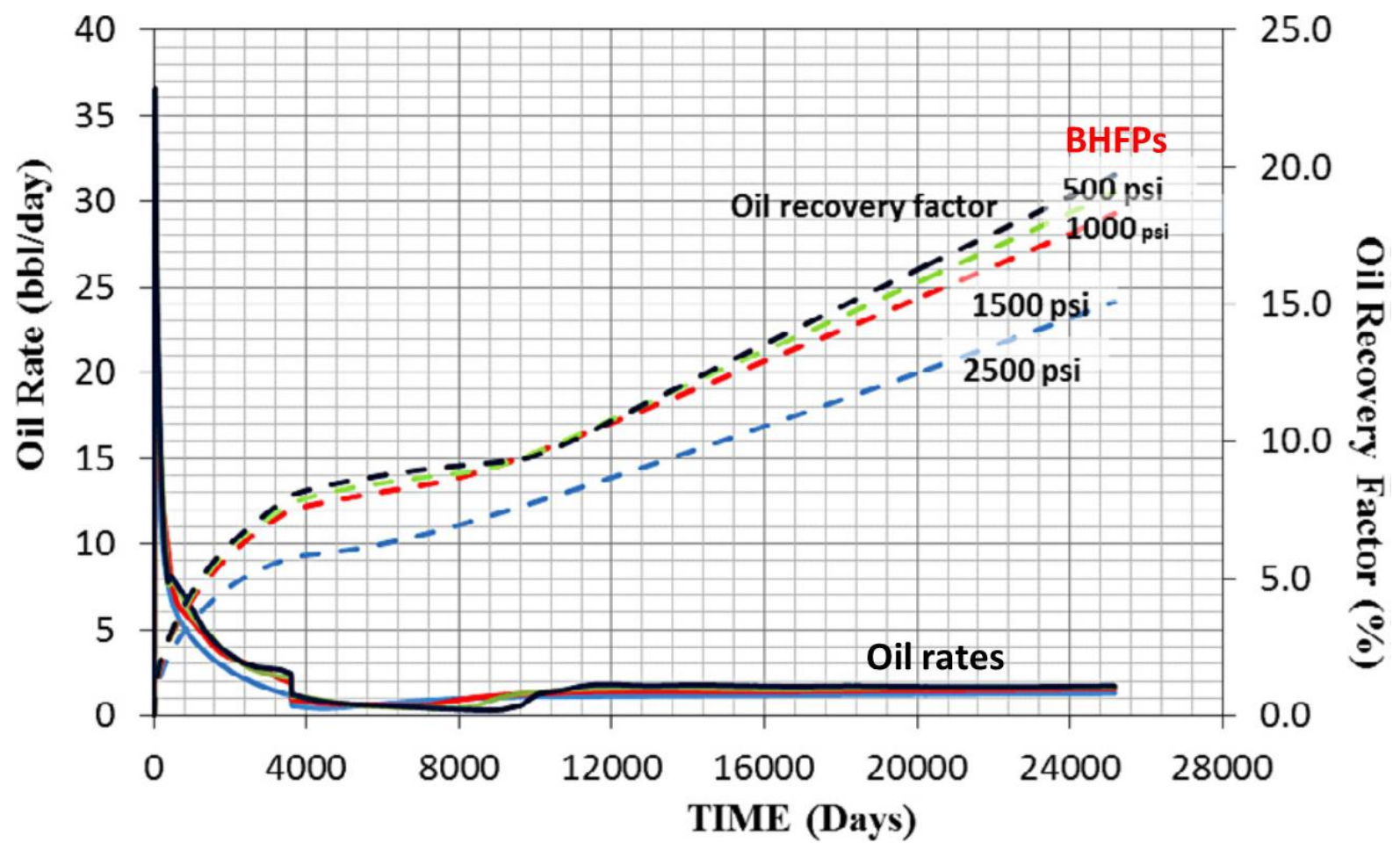

Fig. 2 - Oil rate and recovery at different bottom-hole flowing pressures (marked in the figure) (Sheng and Chen, 2014)

The current available technique to produce gas condensate shale reservoirs is through primary depletion using horizontal wells with multiple transverse fractures. No IOR or EOR methods have been implemented in shale reservoirs. Juell and Whitson (2013) did simulation work to find optimal operation conditions for gas condensate shale reservoirs is in the depletion mode. They found that the optimal production strategy for wells producing from highly undersaturated gas condensate reservoirs is likely to have an initial period where the flowing pressure equals the 
saturation pressure, followed by a gradual increase in drawdown, towards the minimum bottomhole pressure that is operationally possible. When that occurs, the liquid oil will be accumulated at the wellbore, and the resulting gas saturation will be low. Then gas condensate rate will be lower, and the corresponding liquid oil rate will be low as well. To solve this problem, the condensate in conventional condensate reservoirs is re-vaporized by lean gas flooding (Standing et al., 1948; Weinaug and Cordell, 1949; Smith and Yarborough, 1968), nitrogen (Aziz, 1982) or $\mathrm{CO}_{2}$ (Chaback and Williams, 1994; Goricnik et al., 1995).

However, in shale and tight reservoirs, formation permeability is so low that any flooding (gas flooding and waterflooding) may not be feasible because the pressure drop from an injector to a producer is large and thus it is very difficult for the pressure to transport from the injector to the producer. For the huff-n-puff, a quick response from gas injection is expected. The injected gas will increase the pressure near the producer thus the drive energy is boosted. The increased pressure may vaporize the liquid dropout near the producer. However, there was a concern that the injected gas during the huff period will be re-produced during the puff period. This is a hypothesis.

To solve the low-permeability problem, to increase the production drawdown (production rate), and to increase liquid oil offtake, the following preferred scheme to produce gas condensate reservoirs is proposed:

- Huff-n-puff gas injection mode,

- Flowing bottom-hole pressure lower than the dew point pressure.

In this paper, simulation approach is used to test the hypothesis first. Then detailed simulation results and analysis are presented to support the above new idea.

\section{[2]Set up of simulation model}

Sheng and Chen (2014) compared the potentials of gas flooding and huff-n-puff gas injection to enhance oil recovery in shale oil reservoirs. In this simulation work, the same grid model in the earlier study is used, except that gas condensate compositions are used to replace the black oil model. The compositional simulator, GEM, developed by CMG is used. By doing so, the base model used in this paper is justified. The gas condensate composition is from Orangi et al. (2011) as re-presented in Table 1, and the simulated related reservoir and fluid parameters are presented in Table 2. The model grid set up is shown in Fig. 3. In Table $1, \mathrm{P}_{c}, \mathrm{~T}_{\mathrm{c}}$ and $\mathrm{V}_{\mathrm{c}}$ are critical pressure, critical temperature and critical volume, respectively, and $\mathrm{MW}$ is molecular weight. Because of flow symmetry, two half-fractures along the left and right boundaries are simulated. These two half-fractures are equivalent one fracture. One half-fracture is connected to the injector, while the other is connected to the producer. A fracture of $2-\mathrm{ft}$ width is used to represent the real fracture of $0.001 \mathrm{ft}$ but the fracture permeability is reduced from $83,000 \mathrm{mD}$ to $46.5 \mathrm{mD}$ based on the concept of equivalent fracture conductivity $\left(\mathrm{k}_{\mathrm{f}} \mathrm{W}_{\mathrm{f}}\right)$ (Rubin 2010). The concept of equivalent fracture conductivity is that the fracture conductivity $\left(\mathrm{k}_{\mathrm{f}} \mathrm{W}_{\mathrm{f}}\right)$ in the model of $46.5 \times 2=83 \mathrm{mD} \cdot \mathrm{ft}$ is equal to the conductivity of real fracture which is $83000 \times 0.001=83 \mathrm{mD} \cdot \mathrm{ft}$. The fracture length is $1000 \mathrm{ft}$. represented by 55 blocks in the $\mathrm{J}$ direction of the simulation grid. The formation height and the fracture height are the same, $200 \mathrm{ft}$., represented by 7 blocks in the K direction. The fracture spacing is $200 \mathrm{ft}$. The locations of two half-fractures in the gas flooding 
mode are in the most-left and most-right blocks in the I direction as shown in Fig. 1 and Fig. 9. The location of a single fracture in the huff-n-puff mode is in the middle of the model, as schematically shown in Fig. 9. Total 22 blocks are used in the I direction in the gas flooding mode and 21 blocks in the I direction for the huff-n-puff mode. For the gas flooding, the injector is located at $\mathrm{I}=1$ and the producer at $\mathrm{I}=22$. For the huff-n-puff, the injector and producer (same well) is located at $I=11$. The well locations in the XY plan are schematically shown in Fig. 9. All the wells are perforated at the bottom layer $(K=7)$ and in the middle in the $\mathrm{J}$ direction $(\mathrm{J}=$ 28). The detailed block sizes are as follows.

The block sizes in feet in the I direction from $\mathrm{I}=1$ to $\mathrm{I}=22$ in the order (gas flooding mode) are: $1, \quad 4, \quad 6, \quad 8, \quad 8, \quad 9, \quad 10, \quad 12, \quad 12, \quad 14, \quad 16$, $16, \quad 14, \quad 12, \quad 12, \quad 10, \quad 9, \quad 8, \quad 8, \quad 6, \quad 4, \quad 1$

The block sizes in feet in the I direction from $\mathrm{I}=1$ to $\mathrm{I}=21$ in the order (primary and huff-n-puff modes) are:

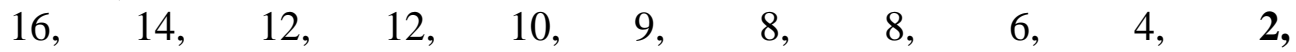

$4, \quad 6, \quad 8, \quad 8, \quad 9, \quad 10, \quad 12, \quad 12, \quad 14, \quad 16$

The block sizes in feet in the $\mathrm{J}$ direction with total 55 blocks (all modes) are:

35,21 blocks at $20 \mathrm{ft}$ each, 16, 10, 8, 6, 4, 2, 4, 6, 8, 10, 16, 21 blocks at $20 \mathrm{ft}$ each, 35

The block sizes in feet in the $\mathrm{K}$ direction from $\mathrm{K}=1$ to $\mathrm{K}=7$ in the order (all modes) are:

$52.8,26.4,14.2,13.2,14.2,26.4,52.8$

In this study, a single well and a single fracture are built in the model for the huff-n-puff and primary modes. In principle, their block sizes in the I direction could be the same as those in the gas flooding mode, if two half-wells and two half-fractures are used. The results are unchanged because of the flow symmetry (Chen, 2013).

Table 1 - Peng-Robinson EOS Fluid Description of Eagle Ford Condensate (Orangi et al., 2011)

\begin{tabular}{|l|r|r|l|r|r|r|}
\hline & $\begin{array}{l}\text { Initial } \\
\text { Composition, } \\
\text { mole fraction }\end{array}$ & $\begin{array}{l}\text { Pc } \\
(\text { atm. })\end{array}$ & $\begin{array}{l}\text { Tc } \\
\text { (deg. }\end{array}$ & $\begin{array}{l}\text { Acentric } \\
\text { Factor, } \\
\text { dimensionless }\end{array}$ & $\begin{array}{l}\text { MW } \\
\text { g/mole }\end{array}$ & $\begin{array}{l}\text { Vc } \\
(1 / \mathrm{mol})\end{array}$ \\
\hline C1 & 0.65882 & 45.4 & 190.6 & 0.013 & 16.04 & 0.099 \\
\hline N2 & 0.00154 & 33.5 & 126.0 & 0.04 & 28.01 & 0.089 \\
\hline C2 & 0.08337 & 48.2 & 305.4 & 0.0986 & 30.07 & 0.148 \\
\hline C3 & 0.0467 & 41.9 & 369.8 & 0.1524 & 44.09 & 0.203 \\
\hline CO2 & 0.02686 & 72.8 & 304.2 & 0.225 & 44.01 & 0.094 \\
\hline IC4 & 0.01045 & 36.0 & 408.1 & 0.1848 & 58.12 & 0.263 \\
\hline NC4 & 0.01825 & 37.5 & 425.2 & 0.201 & 58.12 & 0.255 \\
\hline IC5 & 0.00825 & 33.4 & 460.4 & 0.2223 & 72.15 & 0.306 \\
\hline NC5 & 0.00791 & 33.3 & 469.6 & 0.2539 & 72.15 & 0.304 \\
\hline NC6 & 0.01194 & 32.46 & 507.5 & 0.3007 & 86.18 & 0.344 \\
\hline C7+ & 0.07627 & 27.8 & 584.1 & 0.3673 & 112 & 0.446 \\
\hline
\end{tabular}




\begin{tabular}{|l|r|r|r|r|r|r|}
\hline $\mathrm{C} 11+$ & 0.04551 & 20.2 & 692.1 & 0.5491 & 175 & 0.685 \\
\hline $\mathrm{C} 15+$ & 0.00278 & 17.62 & 737.5 & 0.6435 & 210 & 0.809 \\
\hline $\mathrm{C} 20+$ & 0.00135 & 15.39 & 781.0 & 0.7527 & 250 & 0.942 \\
\hline
\end{tabular}

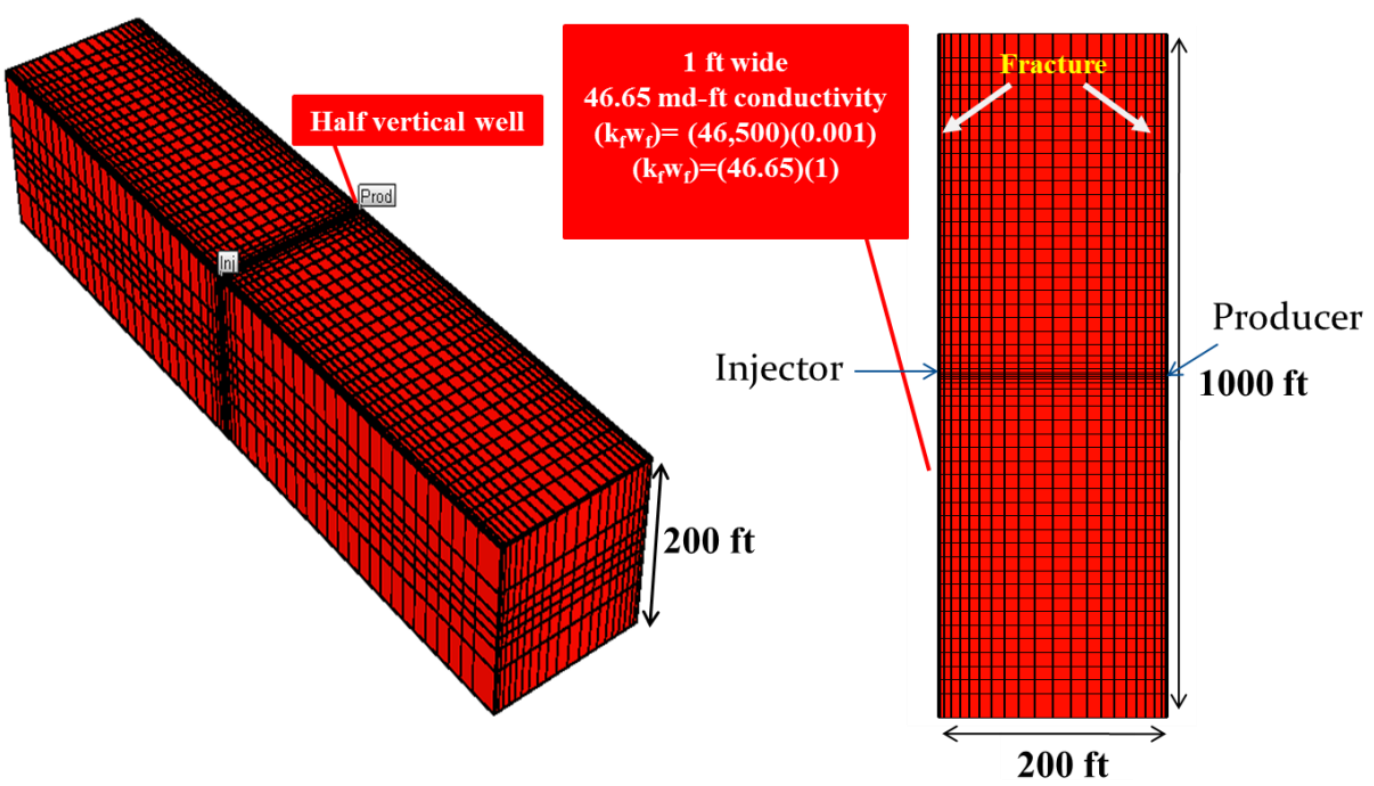

Fig. 3 - Model grid set up

Table 2 - Reservoir and fluid properties used in the model

\begin{tabular}{|c|c|}
\hline Initial Reservoir Pressure & $9088 \mathrm{psi}$ \\
\hline Porosity of Shale Matrix & 0.06 \\
\hline Initial Water Saturation & 0.2 \\
\hline Compressibility of Shale & $5^{*} 10^{-6} \mathrm{psi}^{-1}$ \\
\hline Shale Matrix Permeability & $0.0001 \mathrm{md}$ \\
\hline Reservoir Temperature & $310^{0} \mathrm{~F}$ \\
\hline Reservoir Thickness & $200 \mathrm{ft}$. \\
\hline Dew Point pressure & $3988 \mathrm{psi}$ \\
\hline
\end{tabular}

\section{[3]Simulation results and discussion}

Basically, three scenarios are compared: primary production, gas flooding and huff-n-puff gas injection. In each scenario, primary production is implemented in the first 5 years, followed by 25 years of continued production. In the gas injection and gas huff-n-puff scenarios, the injected gas or recycled gas is methane $\mathrm{C}_{1}$. The minimum bottom hole flowing pressure for the producer is $500 \mathrm{psi}$, and the maximum bottom hole injection pressure for the injector is $9500 \mathrm{psi}$. This injection pressure is a conveniently chosen value and close to the initial reservoir pressure 9088 psi. It is assumed to be below the fracture pressure. For the huff-n-puff mode, the injection and production cycle is 100 days, and there is no soaking time. Table 3 shows the simulation results for these base cases. The ratios of each parameter for the huff-n-puff scenario to that for the gas flooding scenario are also shown in this table. 
Table 3 - Performance comparison of different scenarios (100 nD)

\begin{tabular}{|c|c|c|c|c|}
\hline & Primary & $\begin{array}{l}\text { Gas flooding } \\
\text { (A) }\end{array}$ & $\begin{array}{l}\text { Huff-n-puff } \\
\text { (B) }\end{array}$ & $\begin{array}{l}\text { Ratio } \\
\text { (B/A) }\end{array}$ \\
\hline Total gas produced (MMSCF) & 357.01 & 275.43 & 3133.7 & 11.38 \\
\hline Gas injected (MMSCF) & 0 & 216.36 & 3008.3 & 13.90 \\
\hline Net gas produced (MMSCF) & 357.01 & 59.07 & 125.4 & 2.12 \\
\hline Oil produced (MSTB) & 30.385 & 36.5 & 46.666 & 1.28 \\
\hline Oil recovery factor (\%) & 26 & 31.23 & 39.93 & 1.28 \\
\hline Value of produced oil and gas (MM\$̦) & 4.46654 & 3.88628 & 5.1682 & 1.33 \\
\hline
\end{tabular}

From Table 3, it can be seen that the liquid oil recovery from gas huff-n-puff is $39.93 \%$, almost $14 \%$ higher than that from the primary depletion, and about $8 \%$ higher than the gas flooding scenario. If the oil price is assumed to $\$ 100 / \mathrm{STB}$, and the gas selling price is $\$ 4 / \mathrm{MSCF}$, the huffn-puff scenario also shows the highest revenue. Although the primary depletion has a higher revenue than the gas flooding, the liquid oil recovery is lower. In the economic calculation, the difference in capital investment and facility and operation costs are not included. A discount rate is not included either. If a discount rate is considered, the performance of huff-n-puff will look even better than gas flooding because the former responds to gas injection earlier, as Fig. 4 shows that the cumulative oil produced in the huff-n-puff scenario at the earlier days is higher than that in the gas flooding scenario. The simple economic analysis is conducted to compare the liquid oil production potentials between the huff-n-puff mode and gas flooding mode. A detailed economic analysis should be conducted in a real project.

In the current North American market, the gas supply is higher than the demand. Increasing liquid oil production is operators' interest. The results in Table 3 show that huff-n-puff gas injection can meet the operators' goal. 


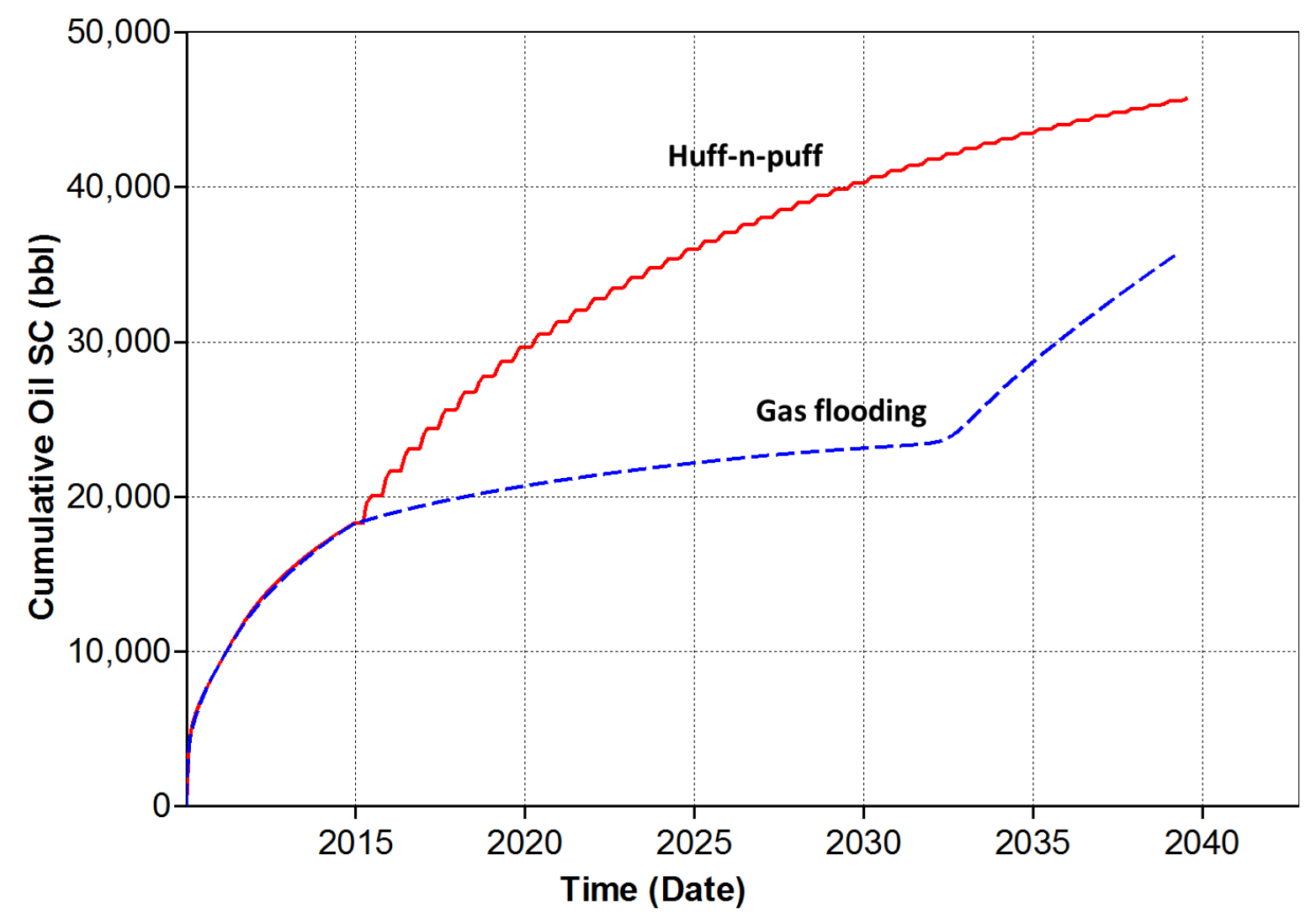

Fig. 4 - Cumulative oil production in the base cases of gas flooding and huff-n-puff

Fig. 5 shows the oil saturations near the producing fractures at Block $(21,28,4)$ for the gas flooding case as marked in Fig. 9, and at Block $(10,28,4)$ in the middle of the model also schematically marked in Fig. 9, but the grids are not correct because the grids in Fig. 9 are for the gas flooding mode not for the huff-n-puff mode. It shows that the oil saturation in the gas huff-npuff case quickly decreases to very low values. At the end, the oil saturation is almost zero. In the primary and gas flooding cases, the oil saturations remain high. Note the oil saturation in the gas flooding case builds up because the oil bank reaches the producing fracture. In the gas huff-npuff case, the oil saturation suddenly shoots up because some oil in the producing fracture is displaced to the block near the fracture during the gas injection period, as shown in Fig. 6 .

Fig. 7 shows the pressures near the producing fracture. It clearly shows that the pressure in the gas huff-n-puff case fluctuates at high and low values following the huff and puff cycles. The pressures in the primary and gas flooding cases remain low. When the flowing bottom-hole pressure is below the dew point pressure, some liquid will drop out during the puff period. But the liquid will be "picked" up by injected dry gas (less heavy components) or mixed with dry gas during huff period. Fig. 8 shows the pressure and oil saturation near the producing fracture in the case of gas huff-n-puff. It clearly shows that as the pressure declines during the puff period, the oil saturation builds up; as the pressure is increased during the huff period, the oil saturation is decreased. 


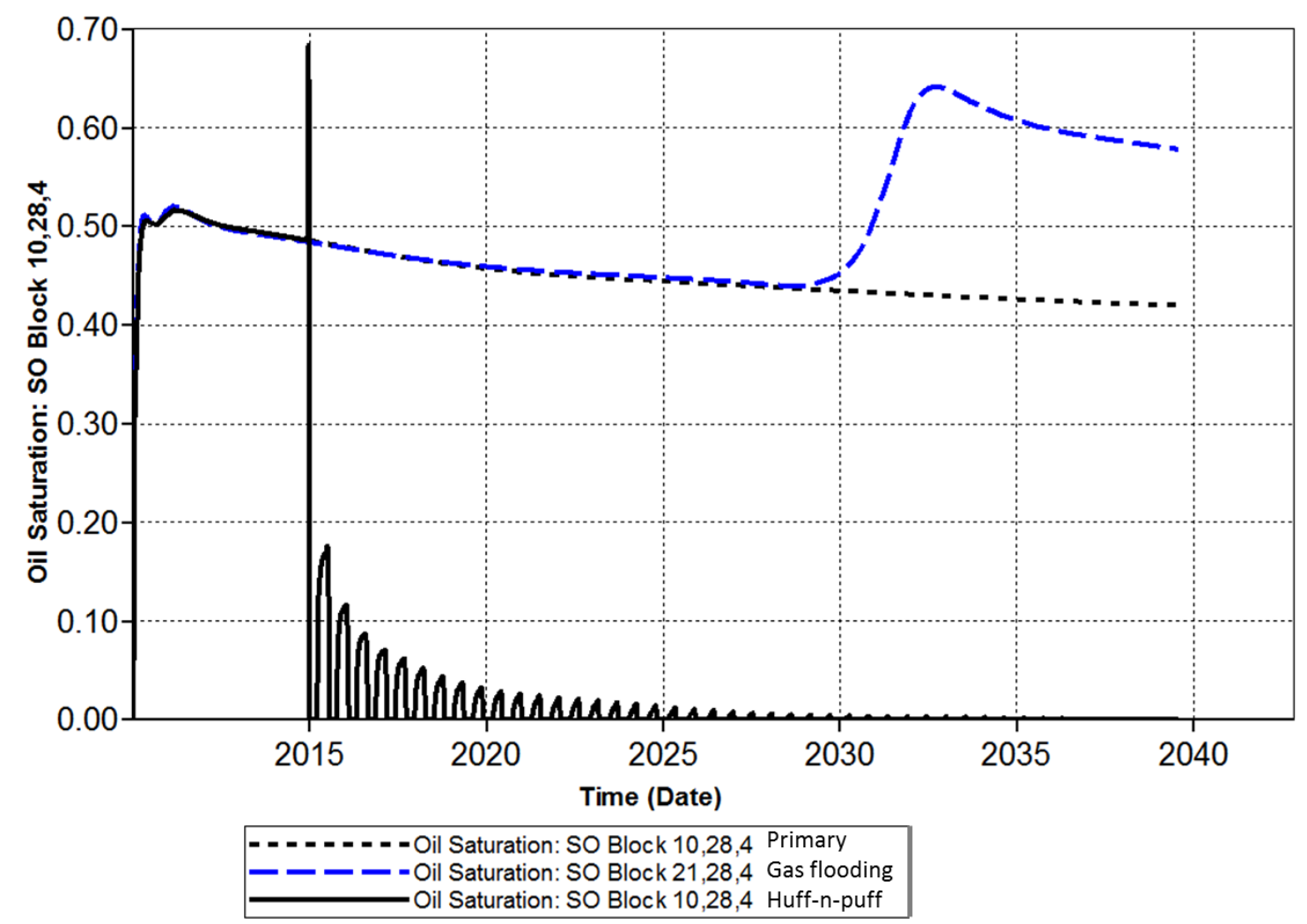

Fig. 5 - Oil saturations near fractures 


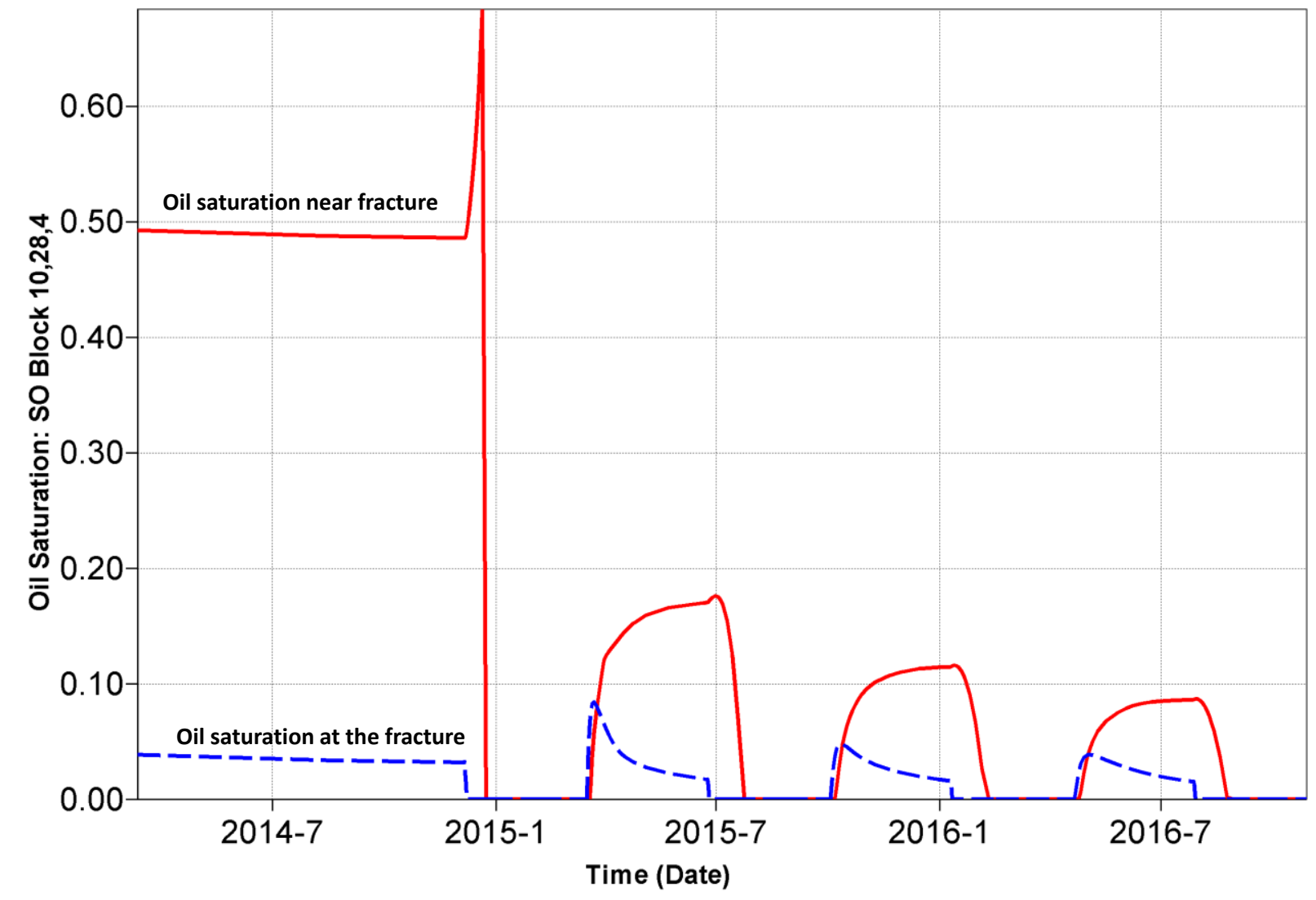

Fig. 6 - oil saturation near $(I=10)$ and at the producing fracture $(I=11)$. 


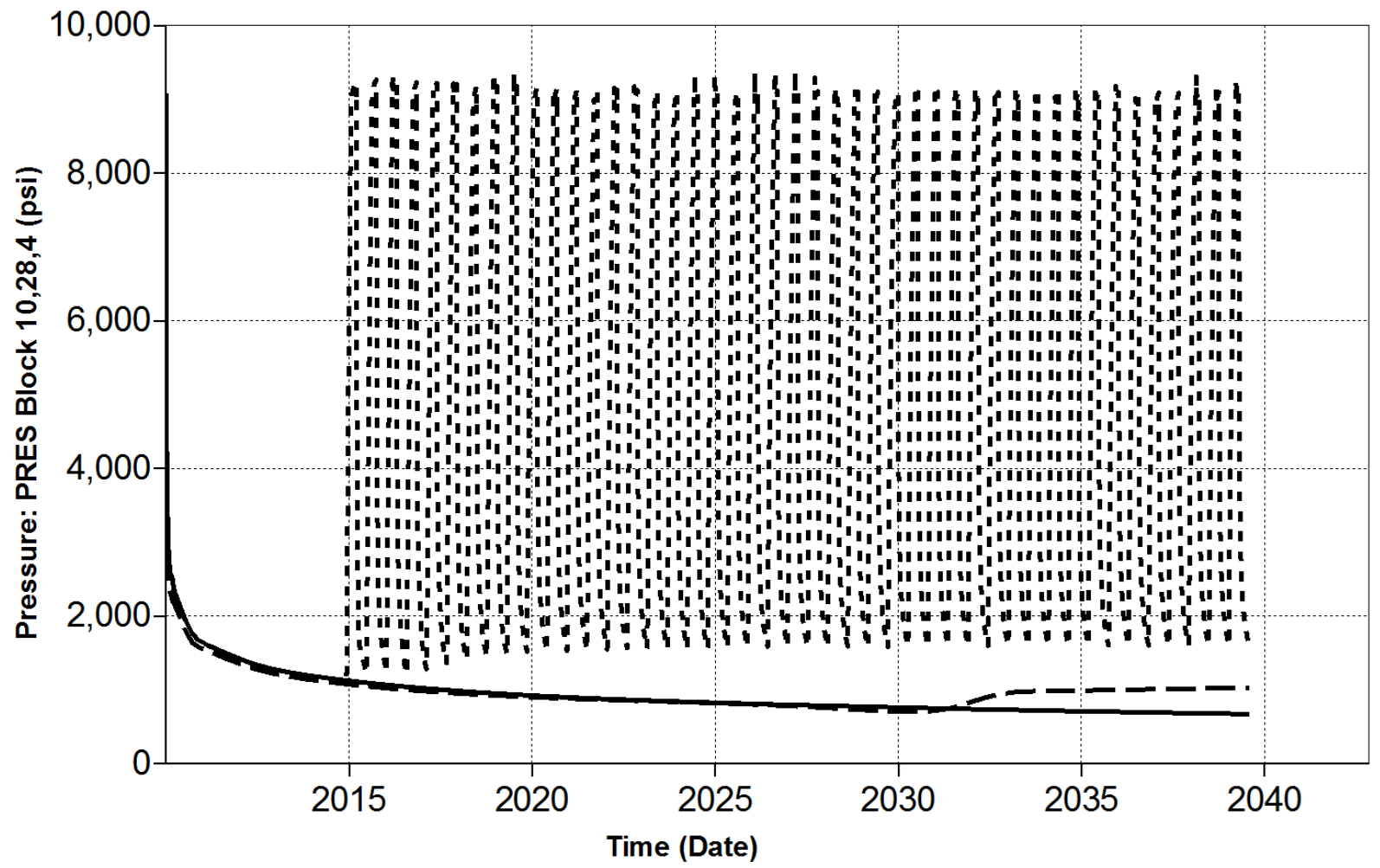

\begin{tabular}{l}
\hline Pressure: PRES Block 10,28,4 Primary \\
\hline - _ _ _ _ _ _ - - - Pressure: PRES Block 21,28,4 Gas flooding
\end{tabular}

Fig. 7 - Pressure near the fractures 


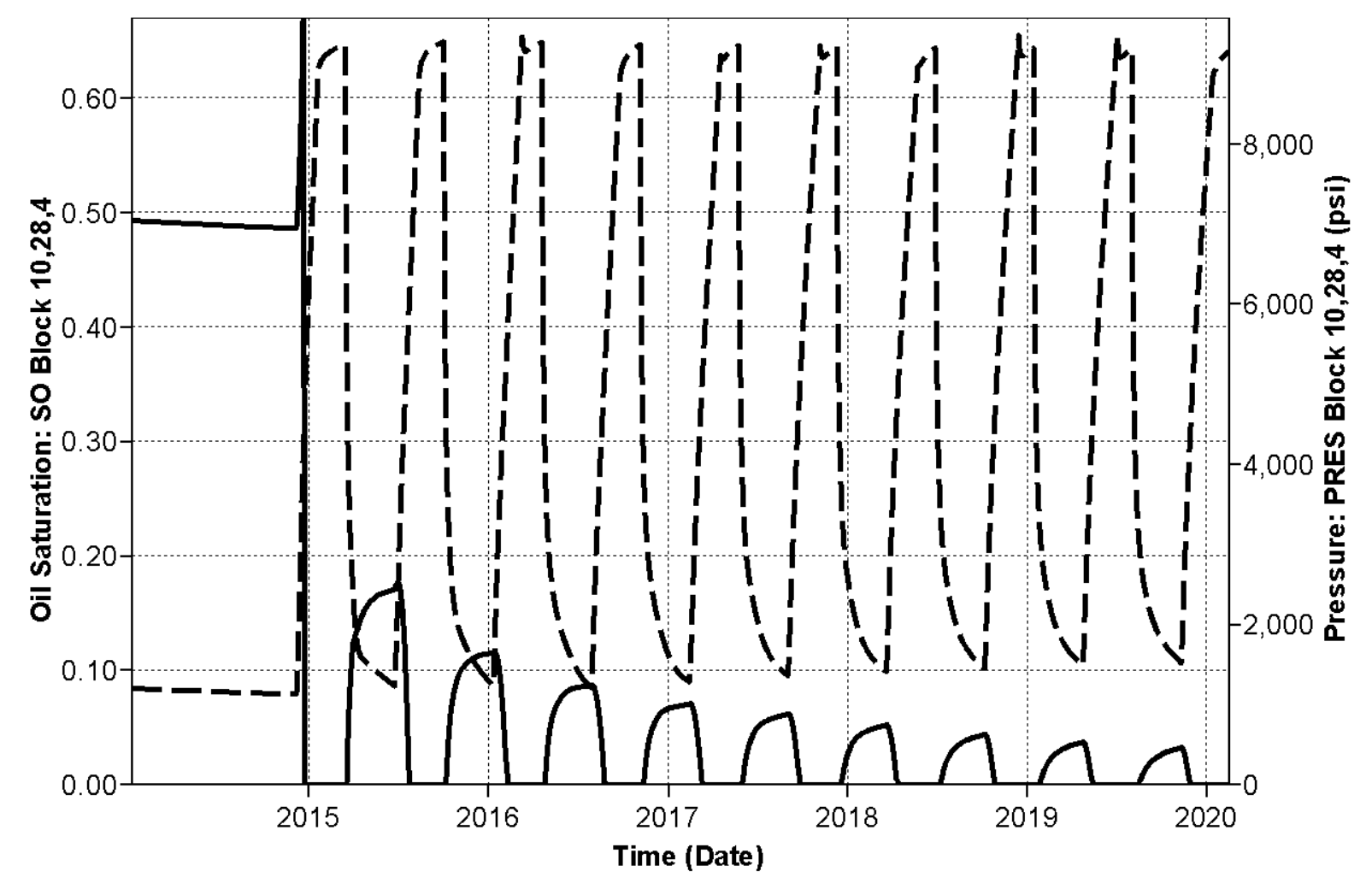

- Oil Saturation: SO Block 10,28,4

Pressure: PRES Block 10,28,4

Fig. 8 - Pressure and oil saturation near the producing fracture in the gas huff-n-puff case

In the conventional or tight reservoirs, gas flooding is used to maintain high pressure so that liquid oil and gas production can be achieved (Thomas et al., 1995). In these cases of shale gas condensate reservoir (matrix permeability of $100 \mathrm{nD}$ ), gas flooding does not result in higher liquid production. This is because the pressure near the injection well is very high, but this pressure cannot propagate to the production end owing to very low permeability. The pressure near the producing fracture (Block $(21,28,4)$ as marked in Fig. 9) in the gas flooding case is very low (about 1000 psi as shown in Fig. 7), but the pressure near the injection fracture (Block $(1,28,4)$ as marked in Fig. 9) is very high $(9500$ psi). It is clear in the pressure map at the end of 10 years of gas flooding, as shown in the left side in Fig. 9. The pressure at the injection side is at $9500 \mathrm{psi}$, while the pressure at the production side is $500 \mathrm{psi}$. And there is a large area in between where the pressure is $4000-6000 \mathrm{psi}$. To further validate this point, the gas flooding case is resimulated by simply increasing the matrix permeability by 1000 times from $100 \mathrm{nD}$ to $0.1 \mathrm{mD}$. The pressure map at the end of 10 years of gas flooding is shown in the right side of Fig. 9. Fig. 9 at the right side shows that the pressure at the injection side is about $2481 \mathrm{psi}$, and the pressure at the production side is $500 \mathrm{psi}$. And the pressure gradually propagates from the injector to the producer. Note that in the case of $0.1 \mathrm{mD}$, the pressure near the injector cannot be built up to 9500 psi like the case of $100 \mathrm{nD}$, because the pressure is able to dissipate to the production end. 


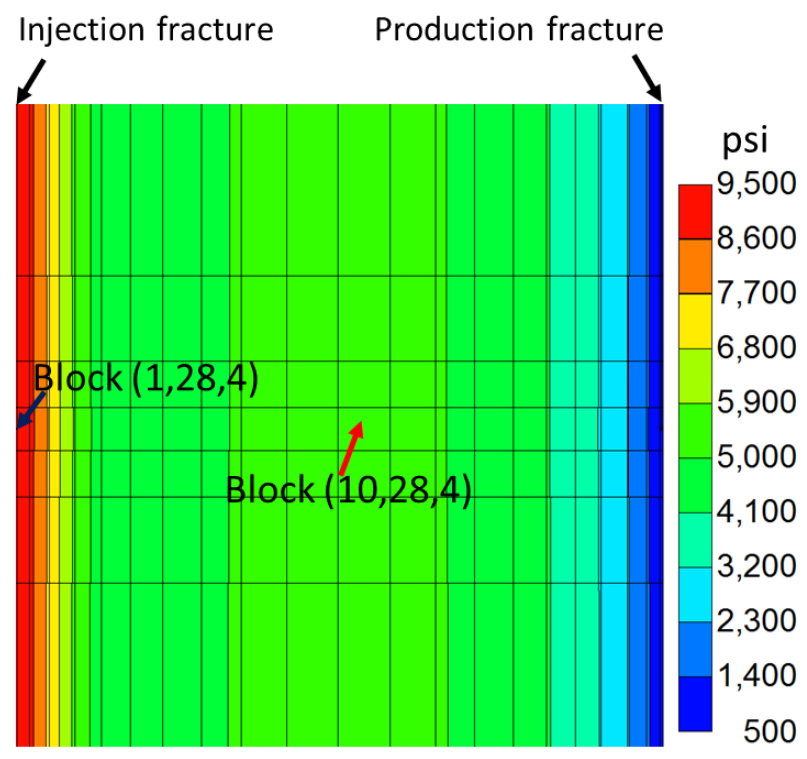

Pressure maps at end 10 yrs injection ( $k=100 \mathrm{nD})$

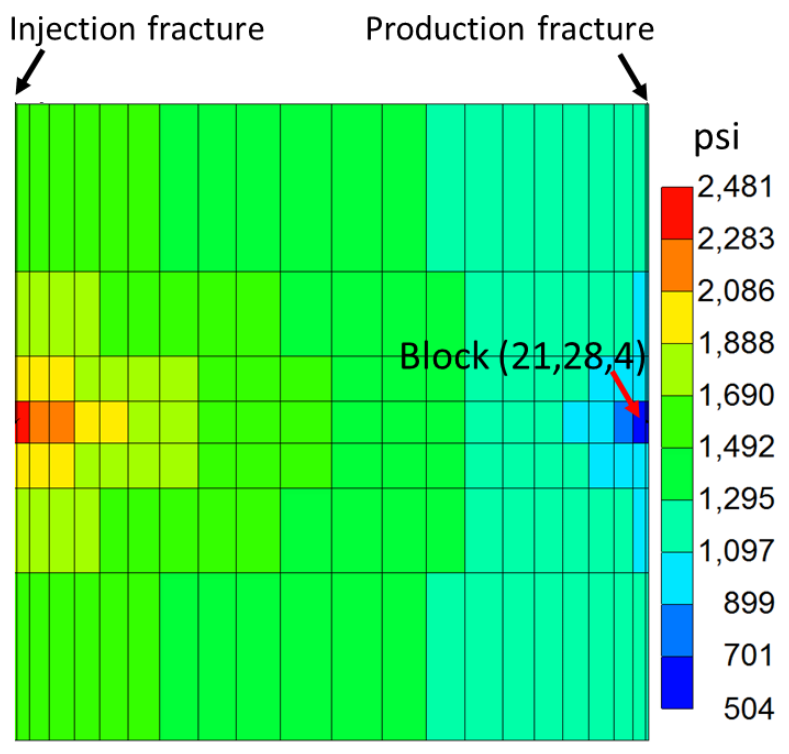

Pressure maps at end 10 yrs injection $(k=0.1 \mathrm{mD})$

Fig. 9 - Pressure distributions at the end of 10 year injection for two permeability reservoirs

To further understand the difference between a conventional or tight reservoir and a shale reservoir, three scenarios of primary, gas flooding and huff-n-puff are re-simulated for a tight formation of $0.1 \mathrm{mD}$. The results for these three cases are shown in Table 4. It shows that the oil recovery factor is the highest in the gas flooding case, twice that from the primary case. The oil recovery factor in the gas hug-n-puff case is lower than that in the gas flooding case. The revenues from produced oil and gas are in line with the oil recovery factors from these three scenarios. The performance difference in Table 3 and Table 4 shows that gas huff-n-puff is a preferred method to increase liquid oil production in shale gas condensate reservoirs, but may not in conventional or tight gas condensate reservoirs. The ratios of each parameter for the huffn-puff scenario to that for the gas flooding scenario in Table 4 are all lower than one except for the net bas produced, compared with the ratios in Table 3 for a shale reservoir which are all greater than one.

Table 4 - Performance comparison of different scenarios $(0.1 \mathrm{mD})$

\begin{tabular}{|l|l|l|l|l|}
\hline & Primary & Gas flooding (A) & Gas huff-n-puff (B) & $\begin{array}{l}\text { Ratio } \\
\text { (B/A) }\end{array}$ \\
\hline Total gas produced (MMSCF) & 427.22 & 7491.5 & 3989.4 & 0.53 \\
\hline Gas injected (MMSCF) & 0 & 7200 & 3600 & 0.50 \\
\hline Net gas produced (MMSCF) & 427.22 & 291.5 & 389.4 & 1.34 \\
\hline Oil produced (MSTB) & 55.046 & 111.36 & 83.167 & 0.75 \\
\hline Oil recovery factor (\%) & 47.1 & 95.28 & 71.16 & 0.75 \\
\hline $\begin{array}{l}\text { Value of produced oil and gas } \\
\text { (MM\$) }\end{array}$ & 7.21348 & 12.302 & 9.8743 & 0.80 \\
\hline
\end{tabular}

\section{[4]Further parametric study}


To further verify this new idea to increase liquid oil production from gas condensate reservoirs, a series of parametric studies are conducted. The parameters studied include initial reservoir pressure, bottom-hole flowing pressure (BHFP), cycle time, soak time, gas compositions, and $\mathrm{CO}_{2}$ injection.

\section{[4.1]Initial reservoir pressure}

The dew point of the gas condensate in the base model is 3988 psi, and the initial reservoir pressure is 9088 psi. It is expected that if the initial reservoir pressure is close to the dew point, the huff-n-puff method should be more effective compared to gas flooding and primary depletion. A lower reservoir pressure of 5000 psi is tested while keep the dew point pressure unchanged. The results for the three scenarios are presented in Table 5. The ratios of oil recovery factors and values of produced oil and gas for the huff-n-puff scenario to those for the gas flooding scenario are all 1.52. These ratios at the initial reservoir pressure of 9088 psi (performance results in Table 3 ) are 1.28 and 1.33, respectively. Comparing these ratios at these two initial reservoir pressures, it can be seen that with lower initial reservoir pressure, the huff-n-puff shows higher potential of improved oil recovery (IOR) compared with gas flooding.

Table 5 - Performance at the initial reservoir pressure of $5000 \mathrm{psi}$

\begin{tabular}{|c|c|c|c|c|}
\hline & Primary & $\begin{array}{l}\text { Gas flooding } \\
\text { (A) }\end{array}$ & $\begin{array}{l}\text { Huff-n-puff } \\
\text { (B) }\end{array}$ & $\begin{array}{l}\text { Ratio } \\
\text { (B/A) }\end{array}$ \\
\hline Total gas produced (MMSCF) & 286.62 & 158.78 & 2125.8 & 13.39 \\
\hline Gas injected (MMSCF) & 0 & 225.51 & 2010.1 & 8.91 \\
\hline Net gas produced (MMSCF) & 286.62 & -66.73 & 115.7 & -1.73 \\
\hline Oil produced (MSTB) & 17.832 & 15.446 & 23.418 & 1.52 \\
\hline Oil recovery factor (\%) & 18.969 & 16.43 & 24.911 & 1.52 \\
\hline Value of produced oil and gas (MM\$) & 2.92968 & 1.2777 & 2.8046 & 2.20 \\
\hline
\end{tabular}

\section{[4.2]Effect of bottom-hole flowing pressure (BHFP)}

As mentioned earlier (see Fig. 2), the oil recovery in shale oil reservoirs should be increased as BHFP is lowered because of larger driving energy. However, Table 6 shows that although the gas produced during the primary depletion is increased in shale gas condensate reservoirs, the oil recovery in both primary depletion and gas flooding increases with BHFP before reaching the dew point pressure (3988 psi in this studied reservoir), and decreases after the dew point. This is because more liquid will drop out when the BHFP is farther below the dew point; and the drawdown will be reduced when the BHFP is increased above the dew point. So the oil recovery factor decreases with BHFP. The ratio oil recovery factors of the huff-n-puff and flooding reaches the lowest point at the dew point pressure (close to 1).

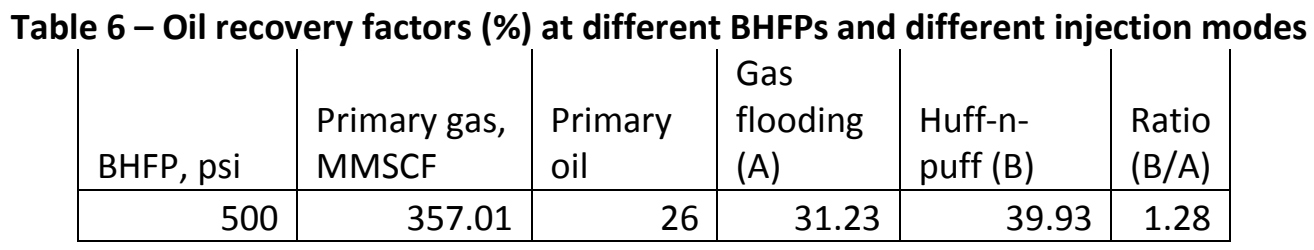




\begin{tabular}{|r|r|r|r|r|r|}
\hline 1000 & 337.87 & 26.427 & 31.757 & 39.328 & 1.24 \\
\hline 2000 & 285.84 & 27.97 & 33.813 & 38.805 & 1.15 \\
\hline 4000 & 167.85 & 28.903 & 35.1 & 34.683 & 0.99 \\
\hline 6000 & 85.132 & 15.272 & 19.972 & 25.322 & 1.27 \\
\hline
\end{tabular}

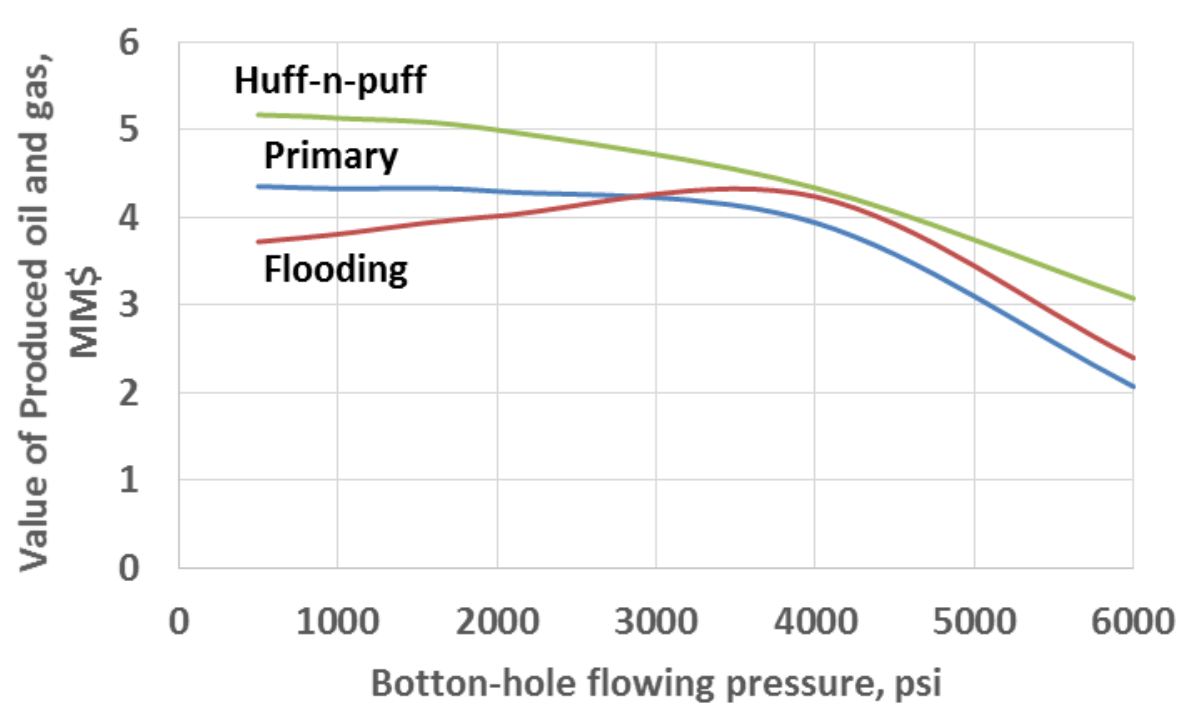

Fig. 10 - Values of produced oil and gas change with BHFP in the different production modes

Fig. 10 shows the values of oil and gas produced in MM\$ at different BHFPs. The value decreases with BHFP in the primary depletion and the huff-n-puff. The value is at the highest at the dew point pressure, and the value increases in the huff-n-putt mode.

\section{[4.3]Cycle time effect}

Fig. 7 shows that the pressure quickly decreases when the well is put in production, and quickly increases when the well is put in injection. After a short time of production or injection, either production or injection rate must quickly decrease. Therefore, reducing cycle time should accelerate production. Table 7 shows the results for different cycle times. Interestingly, the total gas produced follows this expectation, but the total oil produced does not. The data shows that the maximum oil is produced when the cycle time is at 100 days.

Table 7 - Effect of cycle time

\begin{tabular}{|l|r|r|r|r|}
\hline & \multicolumn{1}{|c|}{$200 \mathrm{~d}$} & \multicolumn{1}{c|}{$100 \mathrm{~d}$} & \multicolumn{1}{c|}{$50 \mathrm{~d}$} & \multicolumn{1}{c|}{$25 \mathrm{~d}$} \\
\hline Total gas produced (MMSCF) & 2232.2 & 3133.7 & 3783.1 & 3814.4 \\
\hline Gas injected (MMSCF) & 2161.6 & 3008.3 & 3621.5 & 3572 \\
\hline Net gas produced (MMSCF) & 70.6 & 125.4 & 161.6 & 242.4 \\
\hline Oil produced (MSTB) & 43.816 & 46.666 & 44.668 & 40.891 \\
\hline Oil recovery factor (\%) & 37.49 & 39.93 & 38.22 & 34.99 \\
\hline Value of produced oil and gas (MM\$) & 4.664 & 5.1682 & 5.1132 & 5.0587 \\
\hline
\end{tabular}




\section{[4.4]Soak time effect}

In most of the cases, the puff period immediately follows the huff period. There is no soak time imposed because it is expected that miscibility or diffusion between the injected gas and in situ gas and condensate is fast. To test this hypothesis, the huff time of 100 days in the base case is split into 50 days of soak time and 50 days of injection time. In other words, during the 100 days, the first 50 days are used to inject gas, then the well is shut-in in the next 50 days. The case is "50 d shut-in, $100 \mathrm{~d}$ open" in Table 8 . The results in the table show that all the parameters are lower in this case compared to the base case without 50 days of soak time (the case " $100 \mathrm{~d}$ " in the table), except the net gas produced. When the diffusion effect is added (in the case of "50 d shut-in, $100 \mathrm{~d}$ open, diffusion"), all the parameters are higher than those in the corresponding case without diffusion. However, the effect is minor, and those parameters are all lower than those in the base case. In the simulation model, only the molecular diffusion is considered in this paper. The molecular binary diffusion coefficients between components in the mixture are calculated by using Sigmund (1976) method.

Table 8 - Effect of soak time

\begin{tabular}{|l|r|r|r|}
\hline Scenario & \multicolumn{1}{|c|}{$100 \mathrm{~d}$} & $\begin{array}{l}50 \mathrm{~d} \text { shut-in, } \\
100 \mathrm{~d} \text { open }\end{array}$ & $\begin{array}{l}50 \mathrm{~d} \text { shut-in, } 100 \mathrm{~d} \\
\text { open, diffusion }\end{array}$ \\
\hline Total gas produced (MMSCF) & 3133.7 & 2017.9 & 2028.2 \\
\hline Gas injected (MMSCF) & 3008.3 & 1798.2 & 1790.3 \\
\hline Net gas produced (MMSCF) & 125.4 & 219.7 & 237.9 \\
\hline Oil produced (MSTB) & 46.666 & 40.582 & 35.92 \\
\hline Oil recovery factor (\%) & 39.93 & 34.72 & 5.0436 \\
\hline Value of produced oil and gas (MM\$) & 5.1682 & 4.937 & \\
\hline
\end{tabular}

\section{[4.5]Gas composition effect}

The gas flooding and huff-n-puff are simulated with the injected gas composition of $85 \% \mathrm{C}_{1}$ and $15 \% \mathrm{C}_{2}$. The results are shown in Table 9 . For the ease of comparison, the oil recovery factor and value of produced oil and gas for the base case $(100 \% \mathrm{C} 1)$ are also listed. It can be understood that as the injection gas composition is closer to the reservoir gas, the recovery will be higher, as shown in this table for the huff-n-puff and gas flooding scenarios. Note the oil recovery factor for the gas mixture injection is slightly lower than that from $100 \% \mathrm{C}_{1}$. The ratios of oil recovery factors and values of produced oil and gas for the mixture of $\mathrm{C}_{1}$ and $\mathrm{C}_{2}$ are higher than those for the $\mathrm{C}_{1}$ only.

Table 9 - Gas composition effect $\left(85 \% \mathrm{C}_{1}, 15 \% \mathrm{C}_{2}\right)$

\begin{tabular}{|l|r|r|r|r|} 
& Primary & Gas flooding (A) & Huff-n-puff (B) & Ratio (B/A) \\
\hline Total gas produced (MMSCF) & 357.01 & 273.680 & 3091.000 & 11.29 \\
\hline Gas injected (MMSCF) & 0 & 211.290 & 2917.600 & 13.81 \\
\hline Net gas produced (MMSCF) & 357.01 & 62.390 & 173.400 & 2.78 \\
\hline Oil produced (MSTB) & 30.385 & 35.504 & 49.297 & 1.39 \\
\hline Oil recovery factor (\%) & 26 & 30.377 & 42.180 & 1.39 \\
\hline
\end{tabular}




\begin{tabular}{|l|r|r|r|r|}
\hline Value of produced oil and gas (MM\$) & 4.467 & 3.800 & 5.623 & 1.48 \\
\hline Base case $\left(100 \% \mathrm{C}_{1}\right.$ ) & & & & \\
\hline Oil recovery factor (\%) & 26.000 & 31.230 & 39.93 & 1.28 \\
\hline Value of produced oil and gas (MM\$) & 4.467 & 3.886 & 5.17 & 1.33 \\
\hline
\end{tabular}

\section{[4.6] $\mathrm{CO}_{2}$ injection performance}

Several attempts have been made to evaluate $\mathrm{CO}_{2}$ EOR potential in shale and tight oil reservoirs (Shoaib and Hoffman, 2009; Wang et al., 2010; Chen et al., 2013; Want et al., 2013; Wan et al., 2014; Gamadi et al., 2014; Yu and Sepehrnoori, 2014). To the best of the author's knowledge, evaluation of $\mathrm{CO}_{2}$ potential to improve liquid oil recovery from shale oil gas condensate reservoirs has not been seen in the literature. Shale reservoirs may serve as good $\mathrm{CO}_{2}$ storage reservoirs. Therefore, it is interesting to see the performance of $\mathrm{CO}_{2}$ injection. Table 10 shows the oil recovery factors for $\mathrm{CO}_{2}$ and $\mathrm{C}_{1}$ injection. The oil recovery factor from the $\mathrm{CO}_{2}$ huff-npuff is higher than that from the $\mathrm{CO}_{2}$ flooding. Interestingly, the oil recovery factor from $\mathrm{C}_{1}$ flooding is higher than that from $\mathrm{CO}_{2}$ flooding; and this observation is also true for the huff-npuff cases.

Table $10-\mathrm{CO}_{2}$ vs. $\mathrm{C}_{1}$ injection

\begin{tabular}{|l|l|l|l|}
\hline & $\begin{array}{l}\text { Gas } \\
\text { flooding } \\
(\mathrm{A})\end{array}$ & $\begin{array}{l}\text { Huff-n-puff } \\
(\mathrm{B})\end{array}$ & $\begin{array}{l}\text { Ratio } \\
(\mathrm{B} / \mathrm{A})\end{array}$ \\
\hline $\mathrm{C}_{1}$ oil recovery factor $(\%)$ & 30.890 & 39.93 & 1.29 \\
\hline $\mathrm{CO}_{2}$ oil recovery factor $(\%)$ & 24.533 & 37.092 & 1.51 \\
\hline
\end{tabular}

It may be easier to understand these observations by comparing the flooding cases. Figs. 11 and 12 shows the oil saturation and pressure near the producing fractures. They indicate that the pressure wave and the oil bank arrive later in the $\mathrm{CO}_{2}$ flooding than in the $\mathrm{C}_{1}$ flooding. Therefore, the cumulative oil produced in the $\mathrm{CO}_{2}$ flooding is delayed. By the way, there is a concern of formation damage owing to asphaltene deposition in shale reservoirs (Shahriar, 2014). 


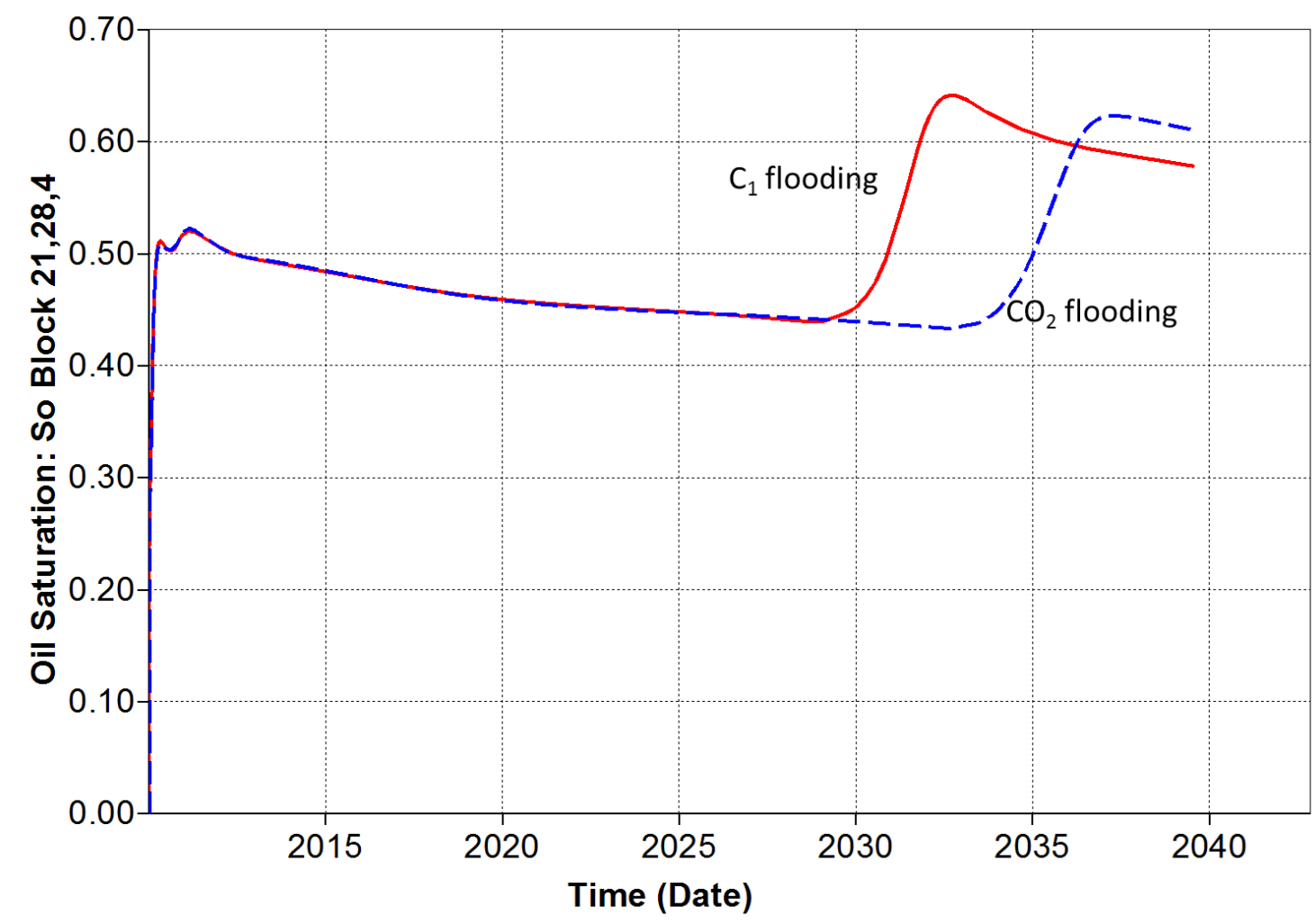

Fig. 11 - Oil saturation near the producing fractures in the $\mathrm{C}_{1}$ flooding and $\mathrm{CO}_{2}$ flooding

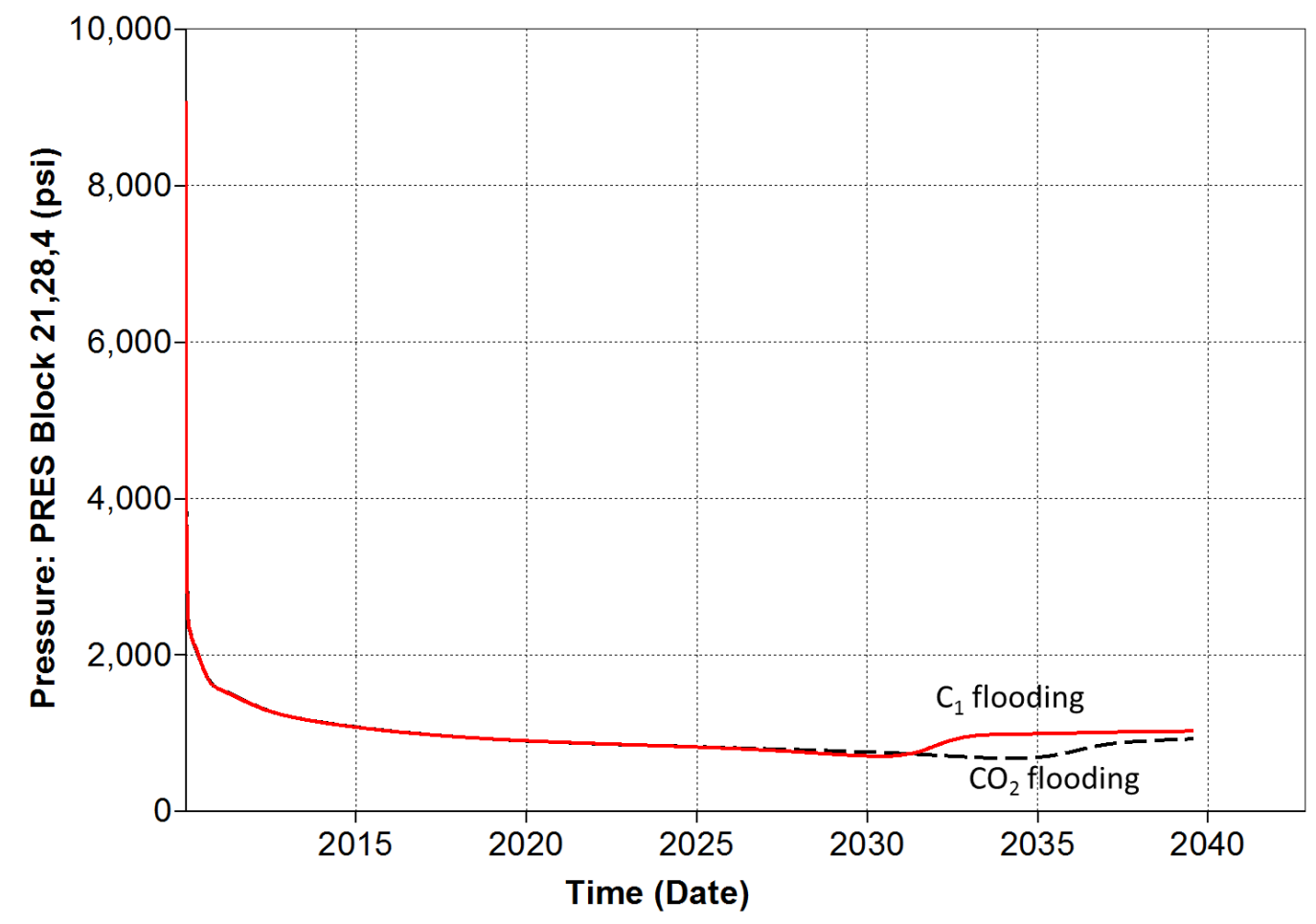

Fig. 12 - Pressure near the producing fractures in the $\mathrm{C}_{1}$ flooding and $\mathrm{CO}_{2}$ flooding 


\section{[5]Conclusions}

Based on this simulation study, the following conclusions or observations may be made.

1. Huff-n-puff injection of produced gases can produce more liquid oil in gas condensate reservoirs than gas flooding or primary depletion. All the cases with different reservoir and fluid properties and operation conditions show this result.

2. The advantages of huff-n-puff over gas flooding are early response to gas injection, high drawdown pressure, oil saturation decrease by evaporation, and overcoming the pressure transport problem owing to ultra-low permeability.

3. The advantages of huff-n-puff over gas flooding become more important when the initial reservoir pressure is close to the dew point pressure, or the bottom-hole flowing pressure is low.

4. $\mathrm{CO}_{2}$ injection may not be superior to lean gases in terms of oil recovery in gas condensate reservoirs.

5. Apparently there is an optimum cycle time for oil recovery; and it may not be necessary to have a soak period.

\section{[6]Acknowledgements}

This material is based upon work supported by the Department of Energy under Award Number DE-FE0024311 and TTU Shale EOR Consortium.

\section{[7]References}

1. Aziz, R.M.A. 1982. Critique on gas cycling operations on gas-condensate reservoirs, paper SPE11477 presented at the Middle East Oil Technical Conference of the Society of Petroleum Engineers held in Manama, Bahrain. March 14-17.

2. Chaback J.J. and Williams, M.L. 1994. p-x Behavior of a rich-gas condensate in admixture with $\mathrm{CO} 2$ and (N2+CO2), SPERE, 9(1), 44-50.

3. Chen, K. 2013. Evaluation of EOR Potential by Gas and Water Injection in Shale Oil Reservoirs, Masters thesis, Texas Tech University, May.

4. Chen, C., Balhoff, B., Mohanty, K. K., 2013. Effect of Reservoir Heterogeneity on Improved Shale Oil Recovery by $\mathrm{CO}_{2}$ Huff-n-Puff, SPE 164553-MS, presented at 2013 SPE Unconventional Resources Conference, Woodlands, Texas, USA, 10-12 April.

5. Gamadi, T.D., Sheng, J.J., and Soliman, M.Y. 2013. An Experimental Study of Cyclic Gas Injection to Improve Shale Oil Recovery, paper SPE 166334 presented at the SPE Annual Technical Conference and Exhibition held in New Orleans, Louisiana, USA, 30 September-2 October.

6. Gamadi, T.D., Sheng, J.J., and Soliman, M.Y., Menouar, H., Watson, M.C., Emadibaladehi, H. 2014. An Experimental Study of Cyclic $\mathrm{CO}_{2}$ Injection to Improve Shale Oil Recovery, paper SPE 169142 presented at the SPE Improved Oil Recovery Symposium, 12-16 April, Tulsa, Oklahoma.

7. Goricnik B., Sarapa, M., and Csisko, M. 1995. Phase equilibria in a rich-gas condensate-CO2 and natural gas mixtures, NAFTA, 46(9), 371-377.

8. Hernandez, I., Farouq Ali, S.M., and Bentsen, R.G. 1999. First Steps for Developing an Improved Recovery Method for a Gas Condensate Reservoir, paper PETSOC 95-09 
presented at the Annual Technical Meeting of Petroleum Society of Canada, June 14 - 18, Calgary, Alberta.

9. Juell, A.O. and Whitson, C.H. 2013. Optimized Well Modeling of Liquid-Rich Shale Reservoirs, paper SPE 166380 presented at the SPE Annual Technical Conference and Exhibition, 30 September-2 October, New Orleans, Louisiana, USA.

10. Orangi, A., Nagarajan, N.R., Honarpour, M.M., Rosenzweig, J. 2011. Unconventional Shale Oil and Gas-Condensate Reservoir Production, Impact of Rock, Fluid, and Hydraulic Fractures. Paper 140536 presented at SPE Hydraulic Fracturing Technology Conference, 2426 January 2011, The Woodlands, Texas, USA.

11. Rubin, B. 2010. Accurate Simulation of Non Darcy Flow in Stimulated Fractured Shale Reservoirs, paper SPE 132093 presented at the SPE Western Regional Meeting, 27-29 May, Anaheim, California.

12. Shahriar, M. 2014. Aggregation of Asphaltene Molecules as a Function of Carbon Dioxide Concentration, PhD dissertation, Texas Tech University, August.

13. Sheng, J.J. 2011. Modern Chemical Enhanced Oil Recovery: Theory and Practice, Elsevier.

14. Sheng, J.J. and Chen, K. 2014. Evaluation of the EOR Potential of Gas and Water Injection in Shale Oil Reservoirs, Journal of Unconventional Oil and Gas Resources, 5, 1-9.

15. Sigmund, P.M. 1976. Prediction of Molecular Diffusion at Reservoir Conditions. Part 1Measurement and Prediction of Binary Dense Gas Diffusion Coefficients. JCPT 15 (2):48-57.

16. Shoaib, S., Hoffman, B.T. 2009. $\mathrm{CO}_{2}$ Flooding the Elm Coulee Field, SPE-123176-MS presented at the SPE Rocky Mountain Petroleum Technology Conference, 14-16 April, Denver, Colorado.

17. Smith L.R. and Yarborough L. 1968. Equilibrium Revaporization of retrograde condensate by dry gas injection, SPEJ, 8(1), 87-94.

18. Standing, M.B., Lindblad, E.N., and Parsons, R.L. 1948. Calculated Recoveries by Cycling from a Retrograde Reservoir of Variable Permeability, Trans. AIME, 174(1), 165-190.

19. Thomas, F.B., Zhou, X., Bennion, D.B., Bennion, D.W. 1995. Towards Optimizing Gas Condensate Reservoirs, paper PETSOC 95-09 presented at the Annual Technical Meeting of Petroleum Society of Canada, June 7 - 9, Calgary, Alberta.

20. Wan, T., Sheng, J.J., and Soliman, M.Y. 2013a. Evaluation of the EOR Potential in Shale Oil Reservoirs by Cyclic Gas Injection, paper SPWLA-D-12-00119 presented at the SPWLA 54th Annual Logging Symposium held in New Orleans, Louisiana, 22-26 June.

21. Wan, T., Sheng, J.J., and Soliman, M.Y. 2013b. Evaluation of the EOR Potential in Fractured Shale Oil Reservoirs by Cyclic Gas Injection, paper SPE 168880 or URTeC 1611383 presented at the Unconventional Resources Technology Conference held in Denver, Colorado, USA, 12-14 August 2013.

22. Wan, T., Meng, X., Sheng, J.J., Watson, M. 2014. Compositional Modeling of EOR Process in Stimulated Shale Oil Reservoirs by Cyclic Gas Injection, paper SPE 169069 presented at the SPE Improved Oil Recovery Symposium, 12-16 April, Tulsa, Oklahoma.

23. Wang, X., Luo, P., Er, V. Huang, S. 2010. Assessment of CO2 Flooding Potential for Bakken Formation, Saskatchewan, paper SPE-137728-MS presented at the Canadian Unconventional Resources and International Petroleum Conference, 19-21 October, Calgary, Alberta, Canada.

24. Weinaug C.P. and Cordell J.C. Revaporization of butane and pentane from sand, Trans. AIME, 179(1), 303-312. 
25. Yu, W., Lashgari, H., Sepehrnoori, K. 2014. Simulation Study of CO2 Huff-n-Puff Process in Bakken Tight Oil Reservoirs, paper SPE 169575-MS presented at the SPE Western North American and Rocky Mountain Joint Meeting, 17-18 April, Denver, Colorado. 